\title{
SHORE PROTECTION USING A FIXED FLOATING RECTANGUL, BREAKWATERS
}

heekal e.m, Koraim a.s

\begin{abstract}
Shore or marina protection using a fixed floating rectangular breakwaters

was examined experimentally for low and moderate waves. Different

parameters affecting the wave diffraction around the proposed structure were

taken into considerations such as, the relative draft and width of the floating

structure, wave characteristics and sea bed slope. The efficiency of the proposed

breakwater model to control the wave energy was measured at different

locations around the structure. It is concluded that; good efficiency of the

proposed model is obtained when the relative draft increases. Also, when the

breakwater width becomes one and half the water depth especially on a sloping

beach of bed slope o
\end{abstract}

